\title{
Children in Foster Care With Challenging Behaviour in Wales (UK): Key Themes and Issues for Practice and Research
}

\author{
Andrew Pithouse \& Kathy Lowe
}

\begin{abstract}
Foster care in Wales (United Kingdom) engages frequently with children thought to present with challenging behaviour. It is essential we gain a deeper understanding of their behaviour in order to inform our thinking about how we provide support to children and carers. The paper presents key findings from research into a total population of fostered children in four neighbouring local authorities in South Wales who were considered to exhibit challenging behaviour. We examine children's characteristics and key processes in fostering and in doing so, we outline the very different behaviours and difficulties associated with these children as perceived by carers. We conclude with some reflection on the term challenging behaviour and its sufficiency to account for difficulties in foster placements.
\end{abstract}

$\mathbf{T}$

his paper presents findings on all fostered children considered to exhibit challenging behaviour located with carers in four local authorities in South Wales. The data are derived from an earlier semi-experimental study by the authors into the outcomes of challenging behaviour training (Pithouse \& Lowe, 2004). We do not cover the same ground here; instead, we examine in more detail the data gathered on the characteristics of those children and also their behaviour as perceived by their carers in order to reveal something of the contemporary nature of fostering in Wales. In doing so we appraise the congruence of the data with what we already know about fostered children and thereby seek to add to what is a relatively slender knowledge base in the UK (particularly Wales) on the characteristics and impact of challenging behaviour in foster care.

In the UK, political and professional interest has risen in recent years as fostering has assumed greater importance in dealing with increasing demands for placements for increasingly difficult children and youngsters. As residential provision reduces across the UK for a variety of reasons, so fostering is assumed to be the preferred alternative for many children. Foster care now comprises a major resource in child and family welfare and provides for an increasing proportion of all children who are taken care of away from the family. At the time of our study there were some 68,000 children in England and Wales who were looked after outside the home (Department for Education and Skills, 2004); the percentage in foster care was $68 \%(41,100)$, which was $14 \%$ more than in 1999 . In Wales, $70 \%$ of 4,315 children looked after by local authorities in 2004 were in foster placements and only $6 \%$ placed in residential care, the remainder were in other settings such as hospital, youth justice, and at home subject to care orders (Welsh Assembly Government 2004). A majority (over 90\%) of foster placements in Wales are provided by the local authority and the remainder by the independent 
sector (Pithouse, Jones, Crowley, Smale, \& Butler, 2000).

Services for fostered children and their carers are now delivered in a fast changing and diverse policy context that reflects different emphases and priorities in a devolved and still devolving UK (National Children's Bureau, 2003). However, most professionals would endorse key principles about fostering set out by the UK government (Department for Education and Skills, 2003) dictating that placements should provide safe and positive care for their duration and in some cases the duration of childhood, given recent trends toward seeking permanence for children in need of family care (Monck, Reynolds, \& Wigfall, 2003). The single biggest challenge to contemporary fostering in Wales is generating sufficient numbers of well trained carers who can create effective attachments in order to promote resilience in children who need to cope with adversity and resist dysfunctional responses to abuse or neglect. These challenges have been the focus of some research and conceptual activity (Schofield, 2001) and connect closely to issues of recruitment, retention, and professional development of carers across the UK. Indeed, as foster care deals increasingly with the needs of more troubled and troublesome children in Wales so it is the case that research, practice and resourcing must seek closer alignment if the ambitions for a safe and effective service are to be realised (Paton, 2003; Hill-Tout, Pithouse, \& Lowe, 2003).

Most carers in Wales and in the UK more generally remain volunteers and receive an income to cover expenses, and most children enter short-term care and return home quickly (Bullock, 2002). A trend toward feepaying in the statutory (i.e., local authority) and particularly independent sector has developed in recent years and a more "professionalised" approach has been taken toward the role and identity of carers and their relationships with agencies (Sinclair, Gibbs, \& Wilson, 2000a). Fostering deals increasingly with children whose needs are very different from those of the general population of children and young people (Keane, 1983). Their mental and physical health and educational attainment typically requires a more treatment-oriented intervention, which in turn calls for additional skilled support from carers if it is to be effective (Hutchinson Asquith \& Simmonds, 2003).

In summary, fostering - whether for brief or extended periods - is increasingly viewed as a skilled and effective intervention, but has yet to be properly funded, supported and researched in Wales, as indeed is the case for the UK as a whole. Research, as one means by which we can promote best practices in fostering, has not kept pace with the full agenda of contemporary out-of-home care. There are particular areas where it remains relatively undeveloped, such as the everyday experience of providing and receiving foster care, notably in relation to behaviour problems particularly in adolescents; maintaining contact with birth parents and siblings; sustaining a child's education; and meeting other social, cultural and health needs (Berridge, 1999). The recruitment, retention, and training of carers requires constant mobilisation of resources and the deployment of effective training methods if carers are to respond to the significant demands placed upon them by children who are often very troubled or troublesome. However, if the move toward more professional foster care is to succeed, we need to know more about the characteristics and behaviours of those children deemed to be challenging. As we demonstrate in this paper, these characteristics and behaviours are areas of some complexity in which many variables can intervene to exacerbate or moderate the demands made on carers by fostered children (Wilson, Sinclair, \& Gibbs., 2003).

\section{Data Sources: Sample and Methods}

Our original study (Pithouse \& Lowe, 2004) focused upon four neighbouring local authorities (out of 22 local authorities in Wales) that were selected because collectively they would be able to generate a study population in excess of 120 fostered children considered to exhibit challenging behaviour. We believed such a population size would be sufficient to identify likely statistical effects of intervention via carer training in behaviour management techniques. The four authorities had similar demographic and environmental features. Their population, predominantly White welsh (98\%), were still adapting to the loss of traditional heavy industry (coal and steel-making) and the arrival of new, primarily low-skill service industries that offered significantly fewer job opportunities for males. Pronounced material deprivation, significantly high unemployment for unskilled men, and communities scarred by drug misuse and family instability were notable in many areas across the four authorities. Proportionately more children became looked after in these four authorities than in the other 18 authorities in Wales.

To aid appropriate identification of the target children, a definition of challenging behaviour was drawn up, based on one developed by Qureshi and Alborz (1992). Children were eligible for the study if their behaviour met any of the following criteria:

- They had at some time caused more than minor injuries to themselves or others.

- Their behaviour had at some time resulted in the destruction of their immediate environment.

- Their challenging behaviour had occurred at least weekly and (a) placed them or others in physical danger, (b) required intervention by more than one adult for control, (c) caused damage that could not be rectified by an immediate carer, or (d) caused at least one hour's disruption.

- They had caused disruption lasting for more than a few minutes at least daily. 
- Their behaviour had resulted in the child being excluded or threatened with exclusion from a public facility because (a) a ban had been or was going to be imposed by the facility, (b) carers were reluctant to accompany the child, or (c) adequate supervision required more than one adult.

- Their behaviour had resulted in the child being apprehended by the police on more than one occasion.

Social work staff at the four authorities identified a total of 114 children who met these criteria. This number represented approximately $28 \%$ of all children fostered by the four authorities who were living within their shared boundaries. While it is not possible to determine whether this percentage is representative of other looked after populations across England and Wales, the study by Pithouse et al. (2000) reported estimates from all local authorities in Wales that between 20 and 60 percent of the children placed away from home were considered as having additional needs by dint of emotional and behavioural problems. Such estimates will vary with the sample studied and methods used; other sources have suggested a range of between one and two thirds of a looked after population having behaviour problems (Quinton, Rushton, Dance, \& Mayes, 1998).

We interviewed foster carers and children's social workers to gather data for child profiles. Child profiles comprised information on age, gender, ethnic origin, diagnosis, health, the natural family, current and previous placements, participation outside the home, behaviour problems, and sources of professional support.

Participation outside the home was measured by a modified version of the Index of Community Integration (Raynes, Sumpton, \& Pettipher, 1989) extended to incorporate items relevant to children and young people, and an exclusion rating. It comprised a list of 17 types of community facilities. Carers were asked how often the child had used each facility in the previous month and to what extent the child's behaviour limited access.

The assessment of behavioural problems was based on a modified version (Lowe, Felce, \& Blackman, 1996) of a section in the Disability Assessment Schedule (Holmes, Shah, \& Wing, 1982). The original list comprised 13 behaviours, modified to give separate ratings on the frequency of occurrence and severity of management problem for each behaviour presented. This list was extended to 48 behaviours, to include the wide range of behaviours cited for the children during initial identification. We assessed carer stress and emotional response to challenging behaviour using the Malaise Inventory (Rutter, Tizard, \& Whitmore, 1970) and a 15-item scale developed by Hastings and Remington (1994).

The foster carers of these 114 children were invited to participate in the study, and 115 agreed; it should be noted that in some households two carers participated in the study and some carers fostered more than one participating child. The importance of carers to outcomes in fostering is of course crucial and much depends upon their warmth toward and interaction with the child (Sinclair \& Wilson, 2003). Likewise, much depends upon the attitude and motivation of the child and whether they are considered to be "difficult" (Schofield, Beck, Sargent, \& Thoburn, 2002). First we briefly identify key characteristics of the carers in order to offer some context for our discussion of the background and conduct of the children.

\section{Headline Characteristics of the Carers}

In Wales as in the UK as a whole, the social characteristics of carers have remained in large part fairly constant, with relatively far fewer lone carers than couples, fewer working women, fewer families with children under age five, relatively fewer black and minority ethnic carers, and women more than men likely to be the registered carer (Triseliotis, Borland, \& Hill., 2000; Sellick \& Connolly, 2002). Our South Wales population of 115 carers shared many of these general characteristics and as with the study by McNeish, Newman, \& Roberts (2002), the majority (over 90\%) lived with a partner or spouse. We might note however that there can be considerable variation in carer characteristics within and between local authorities, and between independent agencies (Sinclair et al., 2000a; Waterhouse \& Brocklesbury, 1999). The average age of carers in our study was 45 years, with the majority (54\%) in their 40 s, $26 \%$ in their 50 s, $14 \%$ in their 30s, and small proportions in their 20s and 70s.

In Wales there are proportionately very few Black or ethnic minority carers and there are sometimes difficulties in matching for children who are unaccompanied asylum-seekers; there are also problems in attracting sufficient Welsh-speaking carers (Perez-del-Aguila, Holland, Faulkner, Connell, \& Hayes, 2003). More than $98 \%$ of the carers in our study could be described as White Welsh, unlike more ethnically mixed carer populations elsewhere in the UK (Sinclair et al.,2000a), with most being Englishspeaking Welsh people. Nearly three-quarters (74\%) were female. More than half $(57 \%)$ had no other paid employment, while $23 \%$ worked part-time and $20 \%$ full-time. A minority $(9 \%)$ had degree-level education or equivalent, while (31\%) had school-level qualifications; $60 \%$ had no formal academic qualifications. Less than one-fifth (18\%) had professional qualifications in a related field, such as teaching or nursing, slightly more than one fourth (26\%) had professional qualifications in fields unrelated to the caring profession, and more than half (56\%) had no professional qualifications at all.

As with other carers in the UK (Wilson, Sinclair, Taylor, Pithouse, \& Sellick, 2004), the vast majority (90\%) had experience in rearing their own children. Carers' households comprised five people on average, usually including 
an adult male partner whose positive potential in a foster care household was not overlooked (Gilligan, 2000; Sellick \& Connolly, 2002). More than half (56\%) lived in households of four or five people, $36 \%$ in households of six or seven, and $7 \%$ in smaller households of two to three people. Less than half $(46 \%)$ lived in small terraced houses, nearly a third (32\%) in semi-detached homes, less than one fifth $(18 \%)$ in detached houses, and very few $(4 \%)$ in large detached properties.

The greatest proportion (32\%) had been fostering for two to four years, $29 \%$ for five to ten years, and $24 \%$ for more than ten years, while $15 \%$ had less than two years experience. Thus the sample contained a fairly durable and experienced population who, by their own estimation, had previously cared for an average of 14 children with challenging behaviour. As with other UK carers (Sellick \& Thoburn, 2002) they drew on considerable experience, albeit this by itself is no predictor of effective fostering (Gorin, 1997) and other qualities are needed to manage difficult behaviour (Wilson et al., 2004). However a minority $(23 \%)$ of carers claimed limited experience in caring for such children. During the course of their fostering career, $65 \%$ had received some form of training in challenging behaviour, while $35 \%$ had received no such training. More than half (57\%) had received an average of four days of training in challenging behaviour during the three years prior to the study, while as many as $43 \%$ had received no such training during that time. For the most part, carers were unable to recall much detail about the content of the training they had received or who had delivered it. Nonetheless, the vast majority $(81 \%)$ believed their past training to be very or fairly useful. While behavioural interventions are thought to be effective in moderating and/or managing some behaviours (Macdonald, 2002; Sinclair \& Wilson, 2003) the positive impact of challenging behaviour training in foster care in England and Wales as discerned in recent studies (Minnis \& Devine, 2001; Pithouse, Hill-Tout, \& Lowe, 2002; Hill-Tout et al., 2003) resists clear demonstration and training per se is no guarantee of good outcomes in foster care (Sinclair, Wilson, \& Gibbs, 2000b).

\section{The Children: Key Findings}

Of the 114 children identified, $60 \%$ were male, and the average age was 11 years, 1 month. As with other UK studies, older children tended to predominate among those considered to have difficult behaviour (Berridge \& Cleaver 1987; Berridge, 1997), thus nearly half (47\%) of those identified were between 11 and 15 years old. Just over one third $(36 \%)$ were between 5 and 10 years old. $10 \%$ were younger than 5 years old and $7 \%$ were 16 years old or older. As elsewhere in Wales (Pithouse et al., 2000), the vast majority $(98 \%)$ were of White British origin.

\section{Health and Disability}

Foster children in the UK tend to be less physically healthy and more likely to suffer chronic conditions than peers. Dental care is sometimes overlooked prior to entry to care and in some cases continues to be overlooked in care (Williams, Jackson, \& Maddocks, 2001). As with other studies in England (Morris, 1998; Sinclair et al., 2000b), our sample contained a sizeable number with a disability according to their care records. Some $41 \%$ had a learning disability (12\% mild, 19\% moderate, and 10\% severe). In addition, $18 \%$ had a physical disability and $11 \%$ a sensory impairment. Less than half $(48 \%)$ were rated as having no form of disability. However, the vast majority $(92 \%)$ were rated as being in good health.

\section{The Birth Family and Contact}

For $78 \%$ of the children in our study both of the birth parents were known to be still living, and for $1 \%$ both were deceased; for $8 \%$, one parent was deceased. Most of the children (94\%) had at least one sibling, with $60 \%$ coming from relatively large families of four or more children. Nearly two-thirds (65\%) had siblings who were also in foster care. Children in foster care still accord significance to family members even if they have not seen much of them (notably fathers). Siblings in particular engender much relevance for a foster child's sense of family belonging (Hepinstall, Bhopal, \& Brannen, 2001; Shaw, 1998; Sinclair et al., 2000b).

Contact, required by the Children Act 1989 in Wales and England, is often assumed to have a positive impact on aspects of attachment between family members (Sanchirico \& Jablonka, 2000). It is possible that contact can also be distressing as well as associated with abuse in some instances (Cleaver 2000; Quinton, Rushton, Dance, \& Mayes, 1997; Sinclair et al., 2000b). In our study, the vast majority (90\%) of foster children had some form of contact with at least one member of their birth family, but the frequency of this contact was weekly or more for only approximately half of the children. Separation from significant adults and infrequent contact can lead to placement disruption (Schofield et al., 2002). Thus it was notable that $21 \%$ had contact on a monthly basis, while $18 \%$ had contact four times each year or less. No contact with either birth parent occurred for $29 \%$ of the children. Only a fourth of the children had any contact with fathers, with only $13 \%$ having contact on a weekly or daily basis. Some $69 \%$ had contact with the mother, with $32 \%$ having contact on a weekly or daily basis, $17 \%$ on a monthly basis and $20 \%$ four times a year or less.

\section{Placement History}

As with other research (Farmer \& Parker, 1991; Sinclair et al., 2000b; Ward \& Skuse, 2001), for a majority of children this was not their first experience of care. For many there had been several trials at home and for a minority there 
appeared to have been a great deal of movement between home and care. For $13 \%$ of children this was the first time they had been in care; $31 \%$ had experienced one previous placement. A further $32 \%$ had experienced two or three previous placements; $19 \%$ between four and seven placements; and $5 \%$ between 10 and 17 . As with other UK foster care research (Harwin \& Owen, 2003), there were many children in this study who appeared to be frequently on the move and unable to develop lasting attachments, continuity of schooling, and friendships. On average the children had experienced 3.3 placements prior to their current situation. For $32 \%$ of the children, the current placement was expected to be long-term, lasting until transition into adulthood, and for $36 \%$ it was short-term. For a further $32 \%$ the placement length was unspecified; this would seem unlikely to lend a sense of clarity around aims and relationships likely to promote stability and attachment (Farmer, 2002).

In $90 \%$ of cases, this was the first time the child had been placed with the current foster carer. In the UK, placements with more disruptions are, among other things, likely to reflect inadequate information provided to carers, poor preparation for placements, and limited participation in planning and reviews (Aldgate \& Hawley, 1986; Berridge 1997; Department of Health Social Services Inspectorate, 1996; Farmer, 2002). Encouragingly, a clear majority of carers in this Welsh study $(66 \%)$ stated that they knew quite a lot of detail about the child's previous placement history; $25 \%$ believed they had incomplete information; and 9\% stated they knew very little.

\section{Participation Outside the Home}

A major factor in placement stability is the extent to which the social environment beyond the foster family can offer the child opportunities for growth and development rather than risk and adversity (Haggerty, Sharrod, Garmezy, \& Rutter, 1996; Whittaker, 2001). In order to explore whether our child population had capacities and support to enable them to engage with others beyond the foster home, we asked carers to what extent the child had used different community facilities in the past month or so and whether or not the child's behaviour had presented any problems in this respect. The facilities used by $90 \%$ or more of children were local shops, schools, cafes, and main shops. More than half (50\%-58\%) had used a cinema, a leisure centre, and a restaurant. Slightly less than half had used a hairdresser and approximately one third (31\%-38\%) had seen their GP, participated in sport, and attended a disco, library, pub, and youth club. Slightly less than one fourth had been to a spectator sport or attended an evening class. Although not a community facility, as such, $4 \%$ were in paid employment.

Problems related to participation outside the home, particularly in education, often pre-date foster care, but high achievement at school is often associated with happiness at school, placement stability, and carers who value education (Jackson \& Martin, 1998; Jackson, 2002). In our study, behaviour was cited as presenting some degree of problem for $72 \%$ of children with respect to schools. More generally, pro-social behaviour is often associated with placement stability and quality of relationship with a carer that can inhibit difficult behaviour (Fenyo, Knapp, $\&$ Baines, 2000). In our population there were behaviour problems for $41 \%$ in relation to local and main shops, with limitations on use or exclusion as a result. Behaviour problems were rated for $12 \%-22 \%$ of children in relation to cafes, leisure centres, cinemas, restaurants, pubs, and GP surgeries. Behaviour appeared to present the smallest number of problems $(10 \%$ of the children or fewer) in sports, youth clubs, discos, libraries, evening classes, and hairdressers. On average, behaviour was cited as a problem in 2.5 facilities per child.

\section{The single biggest challenge to contemporary fostering in Wales is generating sufficient numbers of well trained carers who can create effective attachments in order to promote resilience in children who need to cope with adversity and resist dysfunctional responses to abuse or neglect.}

At this point it is important to note that none of the four local authorities fostering these children offered highly specialist and intensive therapeutic support schemes that might help promote resilience in fostered children and their carers, in order to sustain placements in the community (Hilpern, 2003; Rees, 2002). Thus, it may be that the child's own characteristics and relationships in care and at school and home (Daniel, Wassell, \& Gilligan, 1999; Fenyo et al., 2000) provided sufficient resilience to offset maladaptive responses, thereby allowing a majority of them to participate in the community without too much difficulty. Similarly, the carers may, like others (Flynn, Ghazal, Legault, Vandermeulen, \& Petrick, 2001) have capacities, skills, and warmth to engender such relatively trouble-free attendance at local facilities. In any event, some $24 \%$ of children who were originally identified for the study as having severe challenging behaviour were not cited as a problem in relation to any of the community facilities, and a further $24 \%$ were seen as having problems in relation to one facility only. Behaviour was 
cited as a problem for $20 \%$ of children in relation to two or three facilities, for $11 \%$ in relation to four facilities, and for $21 \%$ in relation to five or more facilities.

While we must interpret these broad findings with some caution, it is notable that almost half of the population had either no difficulties or difficulties in relation to one facility. This finding does not suggest that they did not display behaviour that was difficult in or out of the foster home. Yet it clearly raises interesting questions about the frequency and nature of such behaviour in relation to caring for children in the community and the extent to which attributions such as challenging behaviour can impart meaningful distinctions about children's conduct and the task of foster care-a point we return to later in this discussion.

\section{Behaviour Problems}

Children with challenging behaviour often come from families with parents whose own psychopathology and environmental circumstances create multiple problems in parenting effectively (Quinton \& Rutter, 1988). There have often been changes of family and domicile, and children are likely to have been maltreated and be doing badly at school (Francis, 2000; Sinclair \& Gibbs, 1998; Triseliotis, 1989). Therefore, it is not surprising, as has long been observed by Keane (1983), that foster children are often emotionally disturbed and that behaviour problems cause many fostering breakdowns. However, not all breakdowns are caused by difficult behaviour that may or may not be present, and other factors such as support systems and carer capacities will intervene (Gorin, 1997).

Placements become more vulnerable to breakdown with increased age and increased behavioural or emotional difficulties. By adolescence, the attrition rate can be as high as $60 \%$ (Strathclyde Regional Council, 1991; Triseliotis, Borland, Hill, \& Lambert. 1995). Yet, we still know relatively little about the typical problem behaviours that cause difficulties for carers and their frequency. Our own research found some similarity with the carer experiences reported by Keane (1983). Her study of 139 long-term foster parents revealed that $92 \%$ could recall having to face behaviour problems at some stage of the placement: "Temper tantrums, enuresis, lack of concentration, destructiveness and above all stealing were much more prevalent among the group than among children in the general population" (Keane, 1983, p. 62).

Our 115 carers were asked to rate the fostered child on a list of 48 types of behaviour problem (Lowe et al., 1996), and to indicate how often each had occurred in the past month and the degree of management problem presented. An average of 21 behaviours per child was cited (range 4 to 42 ). The main behaviours cited for $75 \%$ and more of the children were stubbornness, ignoring rules and instructions, non-compliance, temper tantrums, lies, and attention seeking. Cited for approximately two-thirds were noisiness, confrontation, verbal abuse, and moodiness. Behaviours cited for approximately half were storytelling or fantasising, bullying, sulking, physical aggression, damage to property, hyperactivity or restlessness, manipulative behavior, making false allegations, threatening others, wandering away, and inappropriate eating patterns. Approximately one fourth of the children were said to engage in intentional self-injury, stealing outside the home, sexually inappropriate or provocative behaviour, inappropriate urination, begging or demanding money, ritualistic behaviour, and bed wetting. Fewer children, approximately $15 \%$, were said to misuse substances, abscond, be promiscuous, smear faeces, be incontinent, and threaten suicide. Fire setting was reported for $6 \%$.

Such behaviours need to be understood in relation to their frequency and severity. Those rated as occurring frequently for the greatest proportion of children $(40 \%$ to $43 \%)$ were attention seeking and telling lies. Six other behaviours (temper tantrums, ignoring rules and instructions, confrontation, stubbornness, hyperactivity, and fantasising) were rated as frequent for approximately one third of children. A further seven behaviours (verbal abuse, non-compliance, bullying and inciting others, noisiness, moodiness, and inappropriate eating patterns) were rated as frequent for approximately one fourth of children.

When asked which behaviours created the most severe management problems, 12 behaviours were rated for approximately $50 \%$ of the children (verbal abuse, temper tantrums, non-compliance, lies, bullying, inciting others, ignoring rules, confrontation, attention seeking, noisiness, moodiness, and stubbornness). Four behaviours (lying, ignoring rules, confrontation, and attention seeking) were rated as presenting a severe management problem for $20 \%-24 \%$ of children. While we cannot infer some measure of carer experience from their ratings, we can note from these findings that not all behaviours are frequent and that the severity of management problem varies considerably across the population. Thus, as we note in the following discussion, it is perhaps not surprising that measures of carer stress and responses to such behaviour vary markedly.

\section{Challenging Behaviour and Carer Responses}

Common stressors cited by foster carers are the behavioural, emotional, and health problems of the children (Buehler, Cox, \& Cuddeback, 2003). Given that our population of children were deemed to present some degree of challenging behaviour and would likely generate stress for carers, we therefore asked carers to complete the short Malaise Inventory (Rutter et al., 1979), to assess the presence of stress symptoms. The symptoms rated as occurring by the greatest proportion of carers were worry $(37 \%)$, waking unnecessarily early $(27 \%)$, backache $(26 \%)$, and headaches (25\%). More than two thirds 
(69\%) had low scores, indicating the absence of significant stress, with $23 \%$ rating themselves as experiencing none of the listed symptoms.

We also examined carers' emotional responses to challenging behaviour and assessed them on a short 15-item scale developed by Hastings and Remington (1994). Between $38 \%$ and $64 \%$ of carers indicated that, at times, they felt shocked, betrayed, guilty, hopeless, incompetent, helpless, disgusted, nervous, or resigned. The majority of carers (more than 80\%) indicated that, at times, they felt angry, sad or frustrated, with the latter two emotions being those experienced most frequently by $26 \%$ of carers. Such emotional responses are not untypical of carer reactions elsewhere and reinforce the need to provide support mechanisms that offer frequent contact with key professionals, appropriate levels of pay, regular training, and supportive contact with other individual carers or carer groups (Rhodes, Orme, \& Buehler, 2001; Sinclair et al., 2000a). Thus, most carers did not claim symptoms of marked stress and the most frequent experience for $26 \%$ of carers was feeling sad and frustrated about the perceived behaviour of fostered children.

\section{Discussion}

Our study provided a snapshot of all fostered children in four neighboring local authorities in South Wales deemed by social workers to exhibit challenging behaviour. Data were successfully collected on all 114 children who met the study criteria. The likely representativeness of this sample can best be assessed by comparison with other studies, as establishing prevalence, per se, was beyond the remit of the study. Nearly half of the children were aged 11 and 15 years old, with slightly more than one third between 5 and 10 years old and few younger than 5 or older than 16 years of age. There was a 60:40 split between males and females. This finding is in line with other studies that suggest that behavioural problems are usually first noticed once the child starts primary school and peak between the ages of 8 and 15, and that a higher prevalence of behaviour problems are reported for males than females (McGee in Gaoni, Couper, \& Baldwin, 1998).

The children were considered to present with a high level of behavioural challenges, with lies, ignoring rules, confrontation and attention seeking presenting the most prevalent severe management problems. That said, some of the findings reported in this paper raise for us some interesting questions about the nature of challenging behaviour, and about the capacities of carers to cope and agencies to expedite effective plans. While a large number of behaviour difficulties are cited across the child population, it seems evident that a combination of frequency and severity of behaviour problems was not a majority aspect but did arise in respect to a significant proportion (approximately $40 \%$ ) of the study population. Likewise, stress and carer emotional responses to challenging behaviour also suggested that it was a minority of carers who suffered the more severe symptoms and reactions.

These findings offer some insight into the perceived behaviours of children and the difficulties faced by carers, but at the same time they indicate the dangers of attributing any singular meaning to an experience of challenging behaviour. However, we were unable to explore the data further in order to detect any associations between carer characteristics and perceived behaviours. While we have no direct evidence from our study, we would hypothesise that there may possibly be an unrecognised but convenient strain toward viewing some children and young people as "challenging." Such a portmanteau term has wide currency among carers and other professionals and can divert attention from a range of largely unanalysed conduct and influences, as well as obscure the complex interplay of other factors around placement instability, such as carer capacity, training, support, and effective care management, which we comment briefly on in the following section.

In respect of care planning by social workers, we may note that behaviour problems in foster children are more prevalent than among children in the general population, and the greater the number of placements experienced, the more likely children are to display behavioural problems (Keane 1983). The vast majority (87\%) of children in our study had already experienced at least one previous placement, with more than half having experienced two or more. For a third of the children, care planning had not resulted in any specified length of time being indicated in case files for the current placement, a situation likely to exacerbate feelings of uncertainty and vulnerability.

In respect of effective carer support, we know from UK research that this can result in less placement disruption (Berridge \& Cleaver, 1987; Strathclyde, 1988). Other studies have indicated that many social workers appear to lack time and relevant skills in handling behavioural problems (Department of Health, 1985; Cleaver, 1996). It is also known that fostered children want to see more of their social workers (Schofield et al., 2002). Given the nature of this study population-children with perceived severe challenging behaviour and carers working in relative isolation-the most striking result was the paucity of their contact with specialists in behaviour management. Very few children in this study (less than 8\%) had any recent contact with professionals such as educational psychologists who might be able to effect better outcomes (Sinclair \& Wilson, 2003, p. 883). It has long been known that looking after emotionally disturbed children can impose heavy burdens on carers and their families (Aldgate \& Hawley, 1986; Berridge \& Cleaver, 1987; Minty \& Bray, 2001) and, although the majority of foster carers in this study seemed to be relatively free of stress symptoms, some degree of stress was indicated for over one third of them. Indeed, the absence of appropriate support has 
long been identified as a factor most likely to affect recruitment, retention, and quality of foster carers in Wales and England (Audit Commission, 1994).

In regard to carer capacity and the current emphasis on the "professionalisation" of foster caring across the UK (Sinclair et al., 2000a) we can note that while some carers held full or part-time jobs, more than half had no other paid employment, and $82 \%$ had no formal qualifications in any occupation allied to the caring field. The lack of alternative paid employment may, at first sight, suggest that fostering was viewed as the main occupation; however, fewer than one fourth indicated that generating or supplementing an income was an important aspect of their role as foster carers, and this finding would indicate that the carers tended not to view themselves as professional fosterers. That said, as with other UK carers (Ramsay. 1996; Colton \& Williams, 1997) an element of financial reward played an important part in attracting them to fostering and by extension allowed them the financial freedom to put into practice their wish to contribute to the care of the children. Most had experience in rearing their own children and many, although not all, had gained experience in fostering over relatively lengthy periods. Thus, the carers, while mature and long-serving, were not part of any highly trained specialist teams or schemes and few had any qualifications in respect of looking after children. In this context their abilities were largely based upon their experience of fostering and few had additional capacities via any formal knowledge base about behavioural techniques and the care of troubled or troublesome children.

To repeat, less than one fifth of the foster carers in this study had any professional qualifications in the caring field, which indicated that at least four fifths had received no relevant specialised training prior to fostering. Given this, the general paucity of training provided to the carers has to be viewed as a matter for concern, as elsewhere in recent years (Triseliotis et al., 1995; Berridge, 1997). Over one third of the carers had received no training in challenging behaviour; while $57 \%$ had received some form of training in the past three years, this amounted to only about four days in total. Gorin (1997) identified behaviour management as the training topic most requested by carers and, indeed, the carers in this study who had received such training clearly viewed it favourably (Hill-Tout et al., 2003). The study population of children also revealed a high level of disabilities, with just over half having some form of additional disability and learning disability being the most prevalent form of impairment. This is likely to have implications for the nature and type of support and training required by carers, very few of whom claimed any dedicated training in relation to disability.

Training and good interagency support, while necessary, may not always be sufficient to generate effective foster care and positive outcomes for children. Training foster carers in challenging behaviour, while often effective (Macdonald, 2002) has not always proved to have the desired impact upon skill enhancement in carers nor upon conduct modification in children (Minnis \& Devine, 2001: Pithouse et al., 2002). In short, we need to be cognizant of a range of emotional and practical supports that Quinton (2004) delineates comprehensively and which, when tailored to the needs of adults and children, can assist carers to parent effectively.

\section{The recruitment, retention, and training of carers requires constant mobilisation of resources and the deployment of effective training methods if carers are to respond to the significant demands placed upon them by children who are often very troubled or troublesome.}

Likewise, in respect of fostered adolescents, Farmer, Moyes, and Lipscombe (2004) illuminate the complex weave of effects deriving from children's behaviour and characteristics, carer skills in parenting, and quality of support from services. In doing so they note the likely factors that influence outcomes, particularly training for a professional fostering task that can engage with the adolescent's emotional age, their inner feelings, and their past and present family relationships. Particular importance is claimed by Farmer et al (2004) for training around clarity of responsibilities so that carers know, for example, if they are to monitor fostered children's activities outside the home and how to do this. Carers need to have training in responsibilities around any involvement with school; similarly they need to know how to teach fostered children life skills and how they should approach intimate aspects of personal development. Effective training and good quality tailored support are of course undeniable imperatives and while they may not guarantee desired outcomes their absence will increase the chances of placement instability and breakdown (Martin 2004).

There is substantial evidence that the children being looked after in foster care in Wales and England now are very different from those of 25 years ago (Bebbington \& Miles, 1989; Berridge, 1997; Pithouse et al., 2000). Many children now considered for foster care display behavioural or emotional problems and a significant proportion of placements are frequently stressed and prone to failure (Emans \& Robbroeckx, 1997, p. 39). This will 
inevitably make further demands on the experience, caring, and treatment skills of foster carers. Indeed, a number of UK studies provide continuing evidence about the scarcity of foster carers with the necessary skills to take on specific tasks, especially in relation to adolescents and teenagers (Triseliotis et al., 1995; Walker, Hill, \& Triseliotis, 2002). These studies suggest that social workers are often using the first available placement, with the idea of matching carers' skills to children's needs taking lower priority. Such difficulties will impede the way we meet the needs of children and it is possible that difficult behaviour, while not always frequent or severe (as for many children in this study), may come to be seen as the only problem and making this assumption may mask other deficits in carer capacity, training, support, and care management. Thus we need to know much more about why some carers and professionals attribute challenging behaviour to some children and whether or not this perceived conduct and its labelling has its roots in other anterior and complex factors, including resource scarcity and quality. Such a working hypothesis is mooted as a concluding note and as a topic of fruitful future research, which may help identify more clearly the complex interplay of elements that can undermine or sustain foster placements in Wales and elsewhere.

\section{References}

Aldgate, J. \& Hawley, D. (1986). Helping foster families through disruption. Adoption and Fostering, 10(2), 44-49.

Audit Commission. (1994). Seen but not heard: Co-ordinating community child health and social services for children in need. London: HMSO,

Bebbington, A. \& Miles, J. (1989). The background of children who enter local authority care. British Journal of Social Work, 19(5), 349-368.

Berridge, D. \& Cleaver, H. (1987). Foster home breakdown. Oxford: Blackwell.

Berridge, D. (1997). Foster care: A research review. London: HMSO.

Berridge, D. (1999). Work with fostered children and their families. In M. Hill (Ed.), Effective ways of working with children and their families (pp. 240-255). London: Jessica Kingsley.

Buehler, C., Cox, M. E., \& Cuddeback, G. (2003). Foster parents' perceptions of factors that promote or inhibit successful fostering. Qualitative Social Work, 2(1), 61-83

Bullock, R. (2002). Two influences on the effectiveness of foster care: The needs of children and families and arrangements for leaving. London: Nuffield Foundation.

Cleaver, H. (1996). Focus on teenagers: Research into practice. London: Department of Health.

Cleaver, H. (2000). Fostering family contact. London: The Stationery Office.

Colton, M. \& Williams, M. (1997). The nature of foster care: International trends. Adoption and Fostering, 21(1), 44-49.

Daniel, B., Wassell, S. \& Gilligan, R. (1999). Its just common sense isn't it? Exploring ways of putting the theory of resilience into action. Adoption and Fostering, 23(3), 6-15.

Department for Education and Skills (2003). Green paper: Every child matters. London: the Stationery Office.

Department for Education and Skills (2004). DfES choice protects-facts and figures. May 27, 2004.

Department of Health (1985). Social work decisions in childcare. London: HMSO.

Department of Health Social Services Inspectorate (1996). Inspection of local authority fostering 1994-5. London: Department of Health.
Emans, L. \& Robbroeckx, L. (1997). Criteria for foster care placements: Linking research and practice. International Journal of Child and Family Welfare, 97(1), 39-46.

Farmer, E. (2002). Factors related to stability in foster care for adolescents. London: Nuffield Foundation.

Farmer, E., Moyes, S., \& Lipscombe, J. (2004). Fostering adolescents. London: Jessica Kingsley.

Farmer, E. \& Parker, R. (1991). Trials and tribulations. London: HMSO.

Fenyo, A., Knapp, M. \& Baines, B. (2000). Foster care breakdown: A study of a special teenager fostering scheme. In J. Hudson and B. Galloway (Eds.), The state as parent: International research perspectives on interventions with young persons. Dordrecht: Kluwer Academic Publishers.

Flynn, R., Ghazal, H., Legault, L., Vandermeulen, G., \& Petrick, S. (2004). Use of population measures and norms to identify resilient outcomes in young people in care: An exploratory study. Children and Family Social Work, 9(1), 65-81.

Francis, J. (2000). Investing in children's futures: Enhancing the educational arrangements of looked-after children. Child and Family Social Work, 24(3), 241-260.

Gaoni, L., Couper, Q., \& Baldwin, S. (1998). Defining adolescent behaviour disorder: An overview. Journal of Adolescence, 21, 1-13.

Gilligan, R. (2000). Men as foster careers: A neglected resource? Adoption and Fostering, 24(2), 63-69.

Gorin, S. (1997). Time to listen? Views and experiences of family placement. Portsmouth University: SSRIU.

Haggerty, R., Sharrod, L., Garmezy, N., \& Rutter, M. (1996). Stress, risk, and resilience in children and adolescents: Processes, mechanisms and interventions (2nd ed.). Cambridge: Cambridge University Press.

Harwin, J., \& Owen, M. (2003). Making care orders work. London: Stationery Office.

Hastings, R., \& Remington, B. (1994). Rules of engagement: Towards an analysis of staff responses to challenging behaviour. Oxford: Pergamon Press.

Heptinstall, E., Bhopal, K., \& Brannen, J. (2001). Adjusting to a foster family. Adoption and Fostering, 25(4), 6-15.

Hill-Tout, J., Pithouse, A., \& Lowe, K. (2003). Training foster carers in a preventive approach to children who challenge: Mixed messages from research. Adoption and Fostering, 27(1), 47-56.

Hilpern, K. (2003). Fostering a successful approach. Care and Health, 41, $18-19$.

Holmes, N., Shah, A., \& Wing, L. (1982). The disability assessment schedule: A brief screening device for use with the mentally retarded. Psychological Medicine, 2, 879-890.

Hutchinson, B., Asquith, J., \& Simmonds, J. (2003). Skills protect: Towards a professional foster care service, Adoption and Fostering 27(8) 8-13.

Jackson, S. (2002). Late foster placements: A second chance for stability and educational success. London: Nuffield Foundation.

Jackson, S., \& Martin, P. (1998). Surviving the care system: Education and resilience. Journal of Adolescence, 21(5), 569-583.

Keane, A. (1983). Behaviour problems among long-term foster children. Adoption and Fostering, 7(3), 53-62.

Lowe, K., Felce, D., \& Blackman, D. (1996). Challenging behaviour: The effectiveness of specialist support teams. Journal of Intellectual Disability Research, 40, 336-347.

Martin, T. (2004). Supporting roles: Identifying support for foster carers. Research Policy and Planning, 22(3), 25-34.

Macdonald, G. (2002). Helping foster carers to manage challenging behaviour: An evaluation of a cognitive-behavioural training programme for foster carers. London: Nuffield.

McNeish, D., Newman, T., \& Roberts, H. (Eds.) (2002). What works for children. Buckingham: Open University.

Minnis, H., \& Devine, C. (2001). The effect of foster carer training on the emotional and behavioural functioning of looked-after children. Adoption and Fostering, 25(1), 44-54.

Minty, B., \& Bray, S. (2001). Allegations against foster carers: An in-depth study. Child Abuse Review, 10, 336-350. 
Morris, J. (1998). Still missing? The experiences of disabled children and young people living away from their families (Vol. 1). London: Who Cares? Trust.

Monck, E., Reynolds, J., \& Wigfall, V. (2003). The role of concurrent planning: Making permanent placements for young children. London: BAAF.

NCB. (2003). Child policy review 2003: Summary of key policy developments across the four nations. London: National Children's Bureau.

Paton, L. (2003). Every child matters: Summary and analysis of the Green Paper. Child Right (October). London: National Children's Bureau.

Perez-del-Aguila, R., Holland, S., Faulkner, A., Connell, D., \& Hayes, S. (2003). Overview and survey of effectiveness of interventions to promote stability and continuity of care for looked after children. National Assembly for Wales and Cardiff University School of Social Sciences, University of Wales College of Medicine, Morgannwg Health Authority.

Pithouse, A., \& Lowe, K. (2004). Foster carers who care for children with challenging behaviour: A total population study. Adoption and Fostering, 28(3), 20-30,

Pithouse, A., Hill-Tout, J., \& Lowe, K. (2002). Training foster carers in challenging behaviour: A case study in disappointment. Child and Family Social Work, 7(3), 203-214.

Pithouse, A., Jones, E., Crowley, A., Smale, P., \& Butler, I. (2000). A study of placements in Wales. Cardiff: National Assembly for Wales and School of Social Sciences.

Quinton, D. (2004). Supporting parents: Messages from research. London: Jessica Kingsley.

Quinton, D., Rushton, A., Dance, C., \& Mayes, D. (1997). Contact between children placed away from home and their birth parents: Research issues and evidence. Clinical Child Psychology and Psychiatry, 2(3), 393-413.

Quinton, D., Rushton, A., Dance, C. \& Mayes, D. (1998). Joining new families: A study of adoption and fostering in middle childhood. Chichester: Wiley.

Quinton, D., \& Rutter, M. (1988). Parenting breakdown: The making and breaking of inter-generational links. Aldershot: Avebury.

Qureshi, H. \& Alborz, A. (1992). Epidemiology of challenging behaviour. Mental Handicap Research, 5, 130-145.

Ramsay, D. (1996). Recruiting and retaining foster carers: Implications of a professional service in life. Adoption and Fostering, 20(1), 42-46.

Raynes, N., Sumpton, R., \& Pettipher, C. (1989). The index of community involvement. Manchester University: Department of Social Policy and Social Work.

Rees, A. (2002). Evaluation of the forward steps project: A case study, funded by Children in Wales. Cardiff: School of Social Science, Cardiff University.

Rhodes, K., Orme, J. \& Buehler, C. (2001). A comparison of foster parents who quit, consider quitting and plan to continue fostering. Social Services Review, 75(1), 84-115.

Rutter, J., Tizard, J. \& Whitmore, D. (1979). Education health and behaviour. London: Longmans.

Sanchirico, A. \& Jablonka, K. (2000). Keeping foster children connected to their biological parents: The impact of foster parent training and support. Child and Adolescent Social Work Journal, 17(3), 185-203.

Schofield, G. (2001). Resilience and family placement: A lifespan perspective. Adoption and Fostering, 25(3), 6-19.

Schofield, G., Beck, M., Sargent, K., \& Thoburn, J. (2002). Growing up in foster care. London, British Agency of Adoption and Fostering.

Sellick, C. \& Connolly, J. (2002). Independent fostering agencies uncovered: The findings of a national study. Child and Family Social Work, 7(2), 107-120.
Sellick, C. \& Thoburn, J. (2002). Family placement services. In D. McNeish, T. Newman, \& H. Roberts (Eds.), What works for children (pp. 13-36). Buckingham: Open University.

Shaw, C. (1998). Remember my messages...The experiences and views of 2,000 children in public care in the UK. London: Who Cares? Trust.

Sinclair, I., \& Gibbs, I. (1998). Children's homes: A study in diversity. Chichester: Wiley.

Sinclair, I., Gibbs, I., \& Wilson, K. (2000a). Supporting foster placements: Report one. York: University of York.

Sinclair, I., Wilson, K., \& Gibbs, I. (2000b). Supporting foster placements: Report two. York: University of York.

Sinclair, I., \& Wilson, K. (2003). Matches and mismatches: The contribution of carers and children to the success of placements. British Journal of Social Work, 33(7), 871-884.

Strathclyde Regional Council, Social Work Department. (1988). Fostering and adoption disruptions: A preliminary study. Glasgow: Regional Council.

Strathclyde Regional Council, Social Work Department (1991). The outcome of permanent family placements. Edinburgh: Scottish Office.

Triseliotis, J. (1989). Foster care outcomes: A review of key research findings. Adoption and Fostering, 13(1), 5-17.

Triseliotis, J., Borland, M., Hill, M., \& Lambert, L. (1995). Teenagers and the social work services. London: HMSO.

Triseliotis, J., Borland, M., \& Hill, M. (2000). Delivering foster care. London: BAAF.

Walker, M., Hill, M., \& Triseliotis, J. (2002). Testing the limits of foster care: Fostering as an alternative to secure accommodation. London: BAAF.

Ward, H., \& Skuse, T. (2001). Performance targets and stability of placements for children long looked after away from home. Children and Society, 15(3), 233-346.

Waterhouse, S., \& Brocklesbury, E. (1999). Placement choices for children in temporary foster care. London: NFCA.

Welsh Assembly Government. (2004). Personal social services statistics Wales 2003-4. Cardiff: Local Government Data Unit, Cardiff, WAG.

Whittaker, J. (2001). The context of youth violence: Resilience, risk and protection. Social Services Review, 75(4), 683-683.

Williams, J., Jackson, S., \& Maddocks, S. (2001). Case-control study of the health of those looked after by local authorities. Archives of Disease in Childhood, 85(4), 280-285.

Wilson, K., Sinclair, I., \& Gibbs, I. (2003). The trouble with foster care: The impact of stressful events on foster carers. British Journal of Social Work, 30(3), 191-209.

Wilson, K., Sinclair, I., Taylor, C., Pithouse, A., \& Sellcik, C. (2004). Fostering success: An exploration of the research literature in foster care (Knowledge review for SCIE). London: SCIE/Policy Press.

Andrew Pithouse, $\mathrm{PhD}$, is lecturer and researcher, School of Social Sciences, Glamorgan Building, Cardiff University, Cardiff, Wales. Kathy Lowe, PhD, is lecturer and researcher, Unit for Development in Intellectual Disabilities, School of Care Sciences, University of Glamorgan, Pontypridd, Wales. Correspondence regarding this article may be addressed to Kathy.Lowe@Bromor-tr.Wales.NHS.UK or Pithouse@Cardiff.ac.uk.

Manuscript received: June 1, 2006

Revised: June 23, 2006

Accepted: January 30, 2007 